но. Есть глобальные вещи, и во всем этом в большей или меньшей степени участвовал комсомол».

По итогам работы круглого стола решено подготовить и издать книгу.

Aата поступления: 30.05 .2018 г.

ROUND TABLE “OWING TO KOMSOMOL...” DEDICATED TO THE 100TH ANNIVERSARY

OF THE ALL-UNION LENINIST YOUNG COMMUNIST LEAGUE

A. V. KOSTINA

MOSCOW UNIVERSITY FOR THE HUMANITIES

The paper presents a review of the round table that was held on 23rd May, 2018 at Moscow University for the Humanities and was dedicated to the 100th anniversary of the All-Union Leninist Young Communist League.

Keywords: Komsomol; history of Russia; All-Union Leninist Young Communist League; round table; review; Moscow University for the Humanities

Костина Анна Владимировна - доктор философских наук, доктор культурологии, професcop, директор Института фундаментальных и прикладных исследований, заведующая кафедрой философии, культурологии и политологии Московского гуманитарного университета. ААрес: 111395, Россия, г. Москва, ул. Юности, д. 5. Тел.: +7 (499) 374-61-81. Эл. адрес: Anna_Kostina @inbox.ru

Kostina Anna Vladimirovna, Doctor of Philosophy, Doctor of Culturology, Professor, Director, Institute of Fundamental and Applied Research; Head, Department of Philosophy, Cultural and Political Science, Moscow University for the Humanities. Postal address: 5, Yunosti St., Moscow, Russian Federation, 111395. Tel.: +7 (499) 374-61-81.E-mail: Anna_Kostina@inbox.ru

DOI 10.17805/zpu.2018.4.3

\title{
Роль комсомола в развитии научных исследований проблем молодежи в СССР
}

\author{
С. И. ПЛАКСИЙ \\ НАЦИОНАЛЬНЫЙ ИНСТИТУТ БИЗНЕСА, Г. МОСКВА
}

Текст выступления на круглом столе «Благодаря комсомолу...», который прошел 23 мая 2018 г. в Московском гуманитарном университете и был посвящен 100-летнему юбилею ВЛКСМ.

Ключевые слова: комсомол; история СССР; молодежь; ВЛКСМ; история советской науки

$\mathrm{H}$ еблагодарность - великий грех. Сегодня мы собрались в этом зале, чтобы высказать великую благодарность Комсомолу. Многие десятки миллионов людей прошли прекрасную школу, которая позволила сформировать полезные для жизни качества, получили огромную поддержку и пользу от Комсомола. Великое количество людей могли и могут сегодня сказать: «Комсомол для нас не возраст. Комсомол для нас судьба». 
Комсомол поднял юношей и девушек на определенный уровень дичностного развития и социального статуса. В этом и была одна из его ведущих ролей: помогать, поддерживать, поднимать, возвышать.

O себе могу сказать так: после папы с мамой Комсомол в целом и его выдающиеся личности сыграли определяющую роль в том, что я перед вами выступаю в Москве, да еще в ранге профессора, ректора вуза. В конце 1968 г. я был секретарем комитета комсомола большого ракетного корабля «Прозорливый». Мы пришли из четырехмесячного боевого дежурства в Средиземном море. И нам вручили Знамя «Иучшей комсомольской организации Военно-Морского Флота», а мне - Почетную грамоту ЦК ВАКСМ за подписью первого секретаря Евгения Михайловича Тяжельникова. Это было великое событие для более чем трех сотен комсомольцев нашего корабля, а для меня стало еще и судьбоносным.

Вскоре я был избран депутатом Севастопольского городского Совета депутатов трудящихся (единственный моряк срочной службы). А в 1970 г. благодаря Знамени « Аучшей комсомольской организации Военно-Морского Флота», Почетной грамоте ЦК В $\Lambda \mathrm{KCM}$, депутатству и правительственной награде я был принят в созданную в 1969 г. Высшую комсомольскую школу при ЦК ВАКСМ. Во время учебы стал победителем Всесоюзного конкурса студенческих работ по общественным наукам, а в самом конце обучения оказался лауреатом Всесоюзного конкурса молодых ученых. Их проводил ЦК ВАКСМ. В результате в 1974 г. меня оставили в Москве и взяли на работу в социологическую лабораторию Высшей комсомольской школы.

Иетом 1974 г. началась моя комсомольская научная работа. Сначала в ВКШ было Ава исследовательских подразделения: социологическая лаборатория и сектор истории ВАКСМ под руководством Владимира Константиновича Криворученко. Затем были созданы еще два отдела: отдел международного молодежного движения под руководством Виктора Пантелеевича Мошняги и отдел комсомольского строительства под руководством Игоря Михайловича Ильинского.

Немного истории исследований проблем молодежи в СССР. В феврале 1965 г. ЦК В $\Lambda$ КСМ принял постановление «Об участии комсомольских организаций в проведении конкретных социологических исследований по вопросам воспитания молодежи», благодаря которому в стране стали создаваться социологические подразделения.

По инициативе комсомола в 1967 г. была проведена научная конференция «Молодежь и социализм» с участием около 700 философов, социологов, юристов, экономистов, психологов, педагогов. Она дала толчок молодежной науке. В 1975 г. для повышения эффективности исследований проблем молодежи по инициативе руководства комсомола решением ЦК КПСС был создан Совет по координации исследований проблем молодежи при ЦК ВАКСМ и Академии педагогических наук СССР. Он был призван объединить усилия почти 4000 исследователей молодежной проблематики, рассредоточенных примерно в пятистах вузах и отдельных научных подразделениях, в том числе и Академии наук.

Аля систематизации, углубления и координации изучения проблем молодежи в стране на базе научно-исследовательских подразделений Высшей комсомольской школы 26 июля 1976 г. решением ЦК В $\Lambda$ СМ был создан научный центр, который получил статус научно-исследовательского института первой категории при вузе.

Разрозненные, с признаками анархии научные подразделения ВКШ стали преобразовываться в нечто единое. Постепенно сложился крупный научный институт, который вскоре стал известным и авторитетным в исследовании молодежи, истории 
В $\Lambda$ КСМ, молодежного движения не только в Советском Союзе, но и во многих странах мира. Мы сотрудничали не только с разрозненными отдельными родственными структурами в нашей стране и в социалистических странах, но и в США, Японии, Испании, Италии, Швеции и ряде других стран.

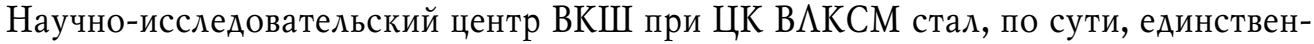
ным в стране учреждением, которое более или менее комплексно изучало проблемы молодежи и молодежного движения. В его штате количество исследователей постепенно достигло 180 человек, среди них было 10 докторов наук и 68 кандидатов наук. Особо плодотворный период в работе Научно-исследовательского центра и Совета по координации исследований проблем молодежи наступил с 1985 г., когда директором НИЦ и главным ученым секретарем совета стал Игорь Михайлович Ильинский. В 14 из 17 секций совета учеными секретарями были работники НИЦ.

Конечно, нельзя идеализировать работу НИЦ, Совета по координации и вообще состояние дел в изучении проблемы молодежи в тот период. И мы это хорошо понимали. В докладе директора НИЦ и главного ученого секретаря Игоря Михайловича Ильинского на заседании Совета по координации научных исследований проблем молодежи при ЦК ВАКСМ, Академии наук СССР, Академии педагогических наук СССР и Министерства образования СССР 22 января 1988 г. преобладали критика и самокритика по поводу положения дел в молодежной науке. Отмечалось, что координационный план совета включал в 1986-1990 гг. 359 тем научных исследований. Совет, и прежде всего НИЦ, стал сотрудничать с родственными структурами в 11 странах мира, раз в два года проводились международные конференции. Был создан международный банк социологической информации. Игорь Михайлович Ильинский стал вице-президентом секции социологии молодежи Международной социологической ассоциации. Под его руководством было проведено три международных социологических исследования.

Однако в докладе Игорь Михайлович Ильинский говорил: «...как и в обществознании в целом, в молодежном цехе преобладал так называемый нормативный подход, в основе которого лежит ориентация на обоснование должного состояния в молодежной среде, в комсомоле вместо анализа реального положения дел, причинно-следственных связей процессов и тенденций... Наука становилась служанкой пустословия.

Социальный императив, требовавший от ученого тщательного взвешивания доли негативного и позитивного, приводил к тому, что за чертой внимания науки оказались многие противоречия, которые приумножались и поэтому не решались ни теоретически, ни практически... Прямо скажем, при всех позитивных результатах и отдельных несомненных успехах положение дел в нашем научном цехе невеселое» (Ильинский, 2017: 189).

Горькие, но справедливые слова. Сегодня можно сказать, оглядываясь на советский период, в том числе перестроечный, что мы, исследователи, были в своем большинстве робкими, а зачастую и приспособленцами. Как правило, исследователи не хотели рисковать своим положением, даже если могли сформулировать острые проблемы. Зачастую все соответствовало тезису «Ученый сверстник Галилея был Галилея не глупее. Он знал, что вертится Земля, но у него была семья». Конечно, мы далеко не все знали и понимали. Однако и трусость присутствовала. Тем более нас одергивали, хотя были и поддерживающие.

Приведу личный пример. Мне неоднократно в 1986-1991 гг. приходилось выступать с лекциями и докладами по проблемам отклоняющегося поведения молодежи, писать статьи и книги на эти и другие острые темы. Аетом 1987 г. я защитил по этой 
теме докторскую диссертацию в Академии общественных наук при ЦК КПСС. Были случаи, когда меня обвиняли, в том числе высокопоставленные деятели, в клевете на советскую молодежь. Хотя, надо сказать, к исследованиям по острой тематике с большим пониманием относились в центральном аппарате КГБ и МВА, где мне неоднократно приходилось выступать. Вместе с тем и мы - исследователи проблем молодежи тоже не можем претендовать на белые одежды и безгрешность.

Но вернемся к докладу Игоря Михайловича Ильинского в 1986 г., где называются причины недостаточной помощи науки в решении назревших проблем молодежи. Он говорил: «...надо признать, что перестройка в обществе, перестройка работы с молодежью, перестройка в комсомоле застала молодежную науку в состоянии, когда она не в силах дать ответ на многие жгучие вопросы...» (там же: 190).

В чем дело? В низком творческом потенциале значительной части исследователей«молодежников»? Аа. В плохой системе стимулирования научного поиска? Во многом. В волюнтаризме некоторых практиков, пренебрежительно относящихся к науке и принимающих решения вне всякой опоры на нее? Увы, это так. В том, что исследователи проблем молодежи, как и вся наша общественная наука, страдают «хвостизмом», спекулятивностью выводов и робостью мысли? «Аа, во многом и это так» (там же).

Как видим, еще в 1986 г. был поставлен, прямо скажем, весьма неутешительный диагноз молодежной науке и кадрам, ею занимающимся, которые в немалом числе не были способны к науке, а лишь с ее помощью зарабатывали себе на жизнь.

Но были и глубинные причинно-следственные основания для неготовности молодежной науки дать адекватный ответы на вызовы времени и более глубокого характера. Игорь Михайлович Ильинский в своем докладе не побоялся их назвать перед руководителями ЦК ВАКСМ и сотнями ведущих исследователей проблем мо-лодежи.

Во-первых, они коренятся во взаимоотношениях молодежной науки и практики педагогической, вузовской, партийной, комсомольской, государственных органов. На протяжении десятилетий укоренилось положение, когда роль науки в работе с молодежью принижалась, когда к ней относились свысока, пренебрежительно. От ученых ждали прежде всего подтверждения научности уже принятых решений. В конечном счете практика имеет ту науку, которой она достойна.

Во-вторых, причиной низкой эффективности молодежной науки является то, что значительная совокупность научных подразделений, тот большой конгломерат отдельных исследователей (1000 человек), являются именно конгломератом, но не представляют собой систему. Наша молодежная наука не может удовлетворять потребности практики.

В-третьих, из-за слабости кадрового потенциала.

Четвертой причиной Игорь Михайлович назвал отсутствие полновесных научных учреждений, недостаточное количество крупных специалистов и отсутствие крупномасштабных междисциплинарных социологических исследований.

Пятой причиной была названа низкая обеспеченность ученых источниками для обоснования выводов (отсутствие статистики, архивов и т. А.). Слишком многое было закрыто и засекречено (там же: 191-193).

Ситуация в молодежной науке в докладе Игоря Михайловича Ильинского на расширенном заседании Совета по координации научных исследований проблем молодежи при ЦК ВАКСМ, Академии наук СССР, Академии педагогических наук СССР, Министерства образования СССР еще в начале перестройки оценивалась объективно и системно. 
Была показана необходимость выработки трезвого, реалистичного, всестороннего взгляда на советскую молодежь, переосмысления различных аспектов отношения общества, государства, партии, комсомола к молодежи, выработки взвешенной системной молодежной политики.

Задача, в частности, состоит в том, чтобы разрушить старые фальшиво-оптимистические, наивно-романтические стереотипы о молодежи и комсомоле, создавать обновленную научную картину молодежной среды и комсомола, не впадая при этом в другую крайность, не рисуя мрачно-нигилистических картин якобы разложившейся молодежи, будто бы разложившегося комсомола (там же: 195).

Большинство выступающих на Совете по координации научных проблем молодежи поддержало основные положения доклада Игоря Михайловича Ильинского, но были и те, кто хотел больше позитива и меньше негатива. Приняли решение кардинально перестроить науку о молодежи. Однако инерцию преодолеть было очень сложно. Энергично занялись перестройкой молодежной науки в Научно-исследовательском центре ВКШ при ЦК В $\Lambda$ КСМ. Были проведены крупномасштабные социологические исследования, подготовлено несколько докладов о положении молодежи в советском обществе.

А 29 октября 1986 г. на научной сессии, посвященной 10-летию НИЦ, в докладе Игоря Михайловича Ильинского была предложена концепция разработки и реализации в СССР молодежной политики, которая должна была стать государственной (Ильинский, 1987).

Обсуждался комплекс практических мер, которые прежде всего высшее партийное и государственное руководство должно было предпринять для разработки и реализации сильной молодежной политики. План включал в себя:

1) создание Государственного комитета СССР по делам молодежи и соответствующих структур на местах, увеличение финансовых и иных вложений в молодежь;

2) разработку Всесоюзной комплексной целевой программы молодежи Страны Советов и подготовку ежегодных докладов по наиболее острым проблемам молодежи;

3) принятие Закона СССР о молодежи.

У этих идей Ильинского было много противников, в том числе облеченных властью. Но время жестких мер против особо инициативных людей было уже позади. И мы прошли все три известные стадии: «Этого не может быть», «В этом что-то есть», «Кто же этого не знает».

Со второй половины 1986 г. Научно-исследовательский центр по решению ЦК В $\Lambda$ КСМ сконцентрировал свою работу на различных аспектах разработки молодежной политики. Центральное место заняли вопросы концепции и подготовки Закона СССР о молодежной политике. Было три основных направления:

1) разработка теоретических и правовых основ молодежной политики;

2) подготовка проекта Закона СССР о молодежи;

3) проведение комплекса исторических, философских и особенно социологических исследований для обоснования необходимости и направлений государственной молодежной подитики.

18 марта 1987 г. И. М. Ильинский направил в ЦК ВАКСМ записку с обосновани-

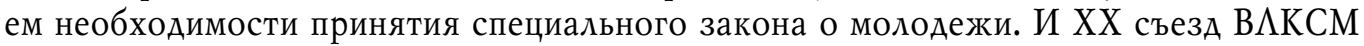
15 апреля 1987 г. идею поддержал. В докладе говорилось: «Всенародное обсуждение проекта данного закона позволило бы выработать конкретную систему мер по повышению роли и ответственности молодежи в решении задач совершенствования социализ- 
ма в нашей стране, ускорения ее социально-экономического развития» (XX съезд ... , 1987: 122).

Вместе с тем ЦК ВАКСМ продолжал прохладно относиться к теме, хотя и позволял НИЦ заниматься вопросами государственной молодежной политики. Понять такую позицию было можно, и мы даже с благодарностью относились к руководству комсомола. Оно разрешало, хотя и подозревало, что может произойти ослабление позиции Союза молодежи, поскольку его возможности и полномочия могли убавиться. Но на ХХ съезде В ККСМ идее закона «О молодежи» «зеленый свет» дал Генеральный секретарь ЦК КПСС М. С. Горбачев, считая, что такой закон укрепит гарантии юношей и девушек.

Итак, идея была поддержана «в верхах». В НИЦе под руководством И. М. Ильинского продолжилась многотрудная и многоаспектная работа по ее реализации.

При этом надо иметь в виду, что идея государственной молодежной политики была снижена до «положения молодежи в обществе». Надо было всячески продвигать в общественное сознание термины «молодежная политика», «государственная молодежная политика» и одновременно разрабатывать ее основы, изучать реальное положение дел в молодежной среде. Были проведены десятки исследований, докладов в ЦК ВАКСМ и других органах. За четыре года сотрудники НИЦ опубликовали около тысячи статей по актуальным проблемам молодежи и комсомола.

Продолжилась труднейшая разработка концепции будущего законопроекта. Проводилось множество дискуссий. Много противников было среди юристов. И 3 августа 1987 г. Бюро ЦК ВАКСМ приняло решение поручить НИЦ ВКШ при ЦК ВАКСМ создать временный творческий научный коллектив (BMTK) для разработки концепции, структуры и текста проекта Закона СССР о молодежи. И. М. Ильинский стал научным руководителем проекта, а руководителем ВМТК была назначена Ажахан Поллыева. Над различными аспектами научного обоснования будущего закона работало большинство сотрудников НИЦ.

Много сил и времени тратилось на преодоление сопротивления «в верхах». И наконец 2 июля 1990 г. на XXVIII съезде КПСС была принята резолюция «О молодежной политике КПСС», где было указано на необходимость скорейшего принятия Закона СССР и законов союзных республик «Об общих началах государственной молодежной политики».

ЦК ВАКСМ стал инициатором создания Комитета по делам молодежи Верховного Совета СССР, а также соответствующих структур в органах исполнительной власти и внес проект Закона СССР «Об общих началах государственной молодежной политики в СССР» на рассмотрение Верховного Совета. Первое обсуждение законопроекта состоялось 9 апреля 1990 г., а принят он был только 16 апреля 1991 г.

От выдвижения И. М. Ильинским идей государственной политики до ее узаконивания прошло более четырех лет серьезной работы и борьбы. Но без поддержки комсомола победы вообще не могло быть. К сожалению, это была последняя победа ЦК В $\Lambda$ КСМ и его Научно-исследовательского центра. С августа 1991 г. начнется новая эпоха не в СССР, а в России. А могло быть и иначе. Закон о государственной молодежной политике, его активная реализация, в том числе комсомолом, могли стать основой новых побед.

Комсомол под давлением извне самоликвидировался. Но от этого ни молодежь, ни наука о ней не выиграли, а только проиграли. Исчез главный разработчик, интегратор и реализатор политики работы с молодежью, ее организатор и социальный лифт. 
Причем проигрыш этот исторический. Он «долгоиграющий». На десятилетия. Конечно, в молодежной среде и объединяющем ее большую часть комсомоле с 1920-х по 1990-е годы было много проблем и противоречий. Все живое не статично и не идеально. Однако «с водой выплеснули и ребенка», которого по большому счету некому стало пестовать и готовить к взрослой активной жизни. В результате проблем в молодежной среде стало не меньше, а на порядок больше. И все это благодаря тому, что больше нет комсомола.

А в нашей активной жизни комсомол был и остается сейчас. Спасибо ему за это. Он был важнейшим фактором нашего развития и совершенствования, личностного, политического и должностного роста.

Последние несколько лет комсомола (1986-1991 гг.) и нашего Научно-исследовательского центра были наполнены надеждой и активной работой. Мы воодушевленно восприняли идеи перестройки, ускорения развития, демократизации, гласности. В Научно-исследовательском центре выделилась довольно большая группа исследователей, способных проводить глубокий анализ процессов, происходящих в стране, партии, комсомоле, молодежной среде. Много выступали в средствах массовой информации. Назову лишь некоторые фамилии: Игорь Михайлович Ильинский, Анатолий Михайлович Блюдин, Галина Ивановна Иноземцева, Владимир Константинович Криворученко, Борис Александрович Ручкин, Евгений Егорович Аевинов, Валентина Федоровна $е$ евичева, Франц Эдмундович Шереги.

У нас не было антисоветчиков или антикомсомольцев. Мы искали пути и писали о том, как улучшить, перестроить комсомол, работу с молодежью, разрешать назревшие противоречия, ориентироваться и удовлетворять различные потребности и интересы молодых людей. Некоторые руководители считали, что мы сгущаем краски. Но жизнь показала, кто был коммунистом, а кто «примазавшимся», ограниченным карьеристом или просто предателем. К сожалению, последних в высшем руководстве страны оказалось немало. Поэтому рухнул Советский Союз и самораспустился комсомол. Но многие из нас - исследователей проблем молодежи - остались советскими комсомольцами. И в этом наша сила.

Спасибо тебе, Комсомол!

\section{СПИСОК АИТЕРАТУРЫ}

Ильинский, И. М. (1987) Проблемы молодежи и молодежной политики в условиях ускорения социально-экономического развития советского общества // Молодежь-86 : сб. ст. М. : НИЦ ВКШ при ЦК В $\Lambda$ СМ. С. 18-34.

Ильинский, И. М. (2017) Государственная молодежная политика в СССР. М. : ИзА-во Московского гуманитарного университета. 432 с.

XX съезд Всесоюзного Аенинского Коммунистического Союза молодежи. Стенографический отчет (1987). М. : Молодая гвардия. 415 с.

Аата поступления: 12.06 .2018 г.

KOMSOMOL'S PART IN THE DEVELOPMENT

OF SCIENTIFIC RESEARCH INTO THE ISSUES OF THE YOUTH

\section{S. I. PLAKSIY}

NATIONAL INSTITUTE OF BUSINESS

The text of the speech at the round table "Owing to Komsomol..." that was held on 23rd May, 2018 at Moscow University for the Humanities and was dedicated to the 100th anniversary of the All-Union Leninist Young Communist League. 
Keywords: Komsomol; history of the USSR; youth; All-Union Leninist Young Communist League; history of Soviet science

\title{
REFERENCES
}

Il'inskii, I. M. (1987) Problemy molodezhi i molodezhnoi politiki v usloviiakh uskoreniia sotsial'no-ekonomicheskogo razvitiia sovetskogo obshchestva. In: Molodezh'-86: sb. st. Moscow, NITs VKSh pri TsK VLKSM. Pp. 18-34. (In Russ.).

Il'inskii, I. M. (2017) Gosudarstvennaia molodezhnaia politika v SSSR. Moscow, Izdatel'stvo Moskovskogo gumanitarnogo universiteta. 432 p. (In Russ.).

XX s'ezd Vsesoiuznogo Leninskogo Kommunisticheskogo Soiuza molodezhi. Stenograficheskii otchet (1987). Moscow, Molodaia gvardiia. 415 p. (In Russ.).

Submission date: 12.06 .2018$.

Плаксий Сергей Иванович - доктор философских наук, профессор, ректор Национального института бизнеса (г. Москва), вице-президент Союза негосударственных вузов Москвы и Московской области, заслуженный деятель науки РФ. Адрес: 111395, Россия, г. Москва, ул. Юности, д. 5, корп. 2. Тел.: +7 (499) 374-75-10. Эл. адрес: n_i_b@mail.ru

Plaksiy Sergey Ivanovich, Doctor of Philosophy, Professor, Rector, National Institute of Business (Moscow), Vice-President, Union of Non-State Universities of Moscow and the Moscow Region, Honoured Scientist of the Russian Federation. Postal address: 5, Bldg. 2, Yunosti St., Moscow, Russian Federation, 111395. Tel.: +7 (499) 374-75-10. E-mail: n_i_b@mail.ru

DOI 10.17805/zpu.2018.4.4

\section{Вдохновляя на творчество}

\author{
А. Д. БОРОДАЙ \\ МОСКОВСКИЙ ГУМАНИТАРНЫЙ УНИВЕРСИТЕТ
}

Текст выступления на круглом столе «Благодаря комсомолу...», который прошел 23 мая 2018 г. в Московском гуманитарном университете и был посвящен 100-летнему юбилею ВЛКСМ.

Ключевые слова: комсомол; творческая молодежь; профессиональное становление; всесоюзные совещания; ВЛКСМ; премия Ленинского комсомола

$\mathrm{B}$ ековой юбилей, который отмечает комсомол в 2018 г., дает повод вернуться к исследованию некоторых страниц его истории. Молодежная организация жила активной жизнью и развивалась более семи десятилетий. Это время было разным. Однако следует сказать, что свою мощь и свои возможности комсомол наилучшим образом продемонстрировал в 70-80-е годы XX столетия. Могу согласиться, что в этом утверждении есть субъективное мнение. Автор этих строк был свидетелем и участником деятельности молодежной организации именно в этот период времени.

Но назову объективные показатели в работе комсомола. В это время численность организации достигла максимума в 42 млн человек. В капитальном строительстве 